\title{
II CONGRESSO INTERNACIONAL DE INTERCULTURALIDADE
}

\author{
São Paulo, 20-22 de septiembre de 2010
}

Durante el mes de septiembre tuvo lugar en São Paulo el segundo congreso internacional sobre interculturalidad organizado por el Instituto Brasileiro de Filosofia e Ciência «Raimundo Lúlio» (São Paulo) y con el patrocinio del Institut Ramon Llull (Barcelona). Este congreso, que ha contado con la presencia de Josep Puig, presidente de la Société Internationale pour l'Étude de la Philosophie Médiévale, ha sido la segunda cita que ha girado en torno a Ramon Llull y la interculturalidad, una continuación del congreso que se efectuó en Andorra y que supuso, como en esta ocasión, un lugar de encuentro entre lulistas de todo el mundo, así como también de especialistas en un ámbito tan de actualidad como el del diálogo intercultural e interreligioso.

Vamireh Chacon (Brasilia, Brasil) inauguró el congreso destacando la universalidad de la obra luliana, que situó en el horizonte de la tradición filosófica de occidente, desde los presocráticos hasta Wittgenstein, resaltando además la influencia de Llull en Gilberto Freire. Esta perspectiva histórica fue complementada por Josep Blanes (Marilia, Brasil), quien puso de relieve, desde una perspectiva sistemática, el amplio alcance y relevancia que tiene la cuestión del debate religioso y la problemática del multiculturalismo y sus distintas manifestaciones y tendencias en el mundo actual, donde la globalización atañe a todos los ámbitos.

Como en la anterior edición, las siguientes contribuciones se estructuraron a través de varios bloques temáticos, que en este caso se centraron, en primer lugar, en la relación entre «Cultura y Religión» y en segundo lugar, entre «Cultura y Sociedades», tal y como explicó Esteve Jaulent, presidente del Instituto Brasileiro de Filosofia e Ciência «Raimundo Lúlio» (São Paulo, Brasil). Él mismo dio inicio a la primera mesa temática sobre cultura y religión, señalando cuán íntimamente están ligados en el pensamiento de Ramon Llull cultura y cristianismo. Así, Esteve Jaulent mostró cómo la definición luliana del hombre como «animal homificant» equivaldría a un proyecto cristianizador del mundo, en tanto que en Cristo se realiza la esencia del hombre. Su intervención fue seguida de cuatro réplicas: En primer lugar, Moacir Amãncio (São Paulo, Brasil) presentó los documentos fundacionales del judaísmo junto con la tradición rabínica, analizando la idiosincrasia de esta religión, que es a la vez civilización y cultura. La segunda réplica, de Celina Lértora (Buenos Aires, Argentina), resaltó lo que tienen en común las tres religiones del libro y lo que tienen de diverso, para explicar que el Libro del gentil es un obra que precisamente plantea la posibilidad de dejar a un lado las diferencias entre estas tres religiones, teniendo en cuenta sus puntos comunes. Tras Celina Lértora, Jamil Iskandar (São Paulo, Brasil) analizó las relaciones entre fe y razón en el Islam y replicó de manera directa a las reflexiones de Esteve Jaulent. De este modo, argumentó que, al igual que pasa con el Cristianismo, el Islam también es portador de un proyecto humanizador. Sheik Mohamad Al Bukai (Damasco, Siria) ofreció la última réplica, abordando de nuevo la estrecha relación entre religión, sociedad y cultura, intentando demostrar cómo esos conceptos, si bien deben diferenciarse analíticamente, forman de hecho un conjunto orgánico indisoluble. Tras este espacio de reflexión se dio paso al debate, en el que se destacó la vertiente política de los conflictos religiosos en tiempos de Llull y en la actualidad, y se puso de relieve la dificultad de establecer fronteras claras entre conceptos tales como religión y cultura.

Este mismo tema vio su continuación la mañana del siguiente día, con la conferencia de Víctor Pallejà (Alicante, España), quien mostró el complejo panorama de identidades y religiones con

Revista Española de Filosofia Medieval, 17 (2010), ISNN: 1133-0902, pp. 211-212 
el que se enfrentaba Llull. Así, desarrolló una topografía de las identidades religiosas del mediterráneo y de su representaciones estéticas y conceptualizaciones a través del tiempo, hasta llegar a Llull. La primera réplica a su exposición nos la ofreció Rui Barros (São Paulo, Brasil), quien destacó la necesidad de distinguir entre la cuestión política y la religiosa, ya que la mayoría de los conflictos históricos supuestamente religiosos han tenido un móvil político. Jean Hubert Cormier (Brasilia, Brasil), a través del pensamiento de Ramon Llull y Tomás de Aquino, nos acercó al análisis del concepto de tolerancia que, lejos de llegar a ser un eufemismo que esconda indiferencia hacia el otro, debe nacer del conocimiento y de la gratitud hacia uno mismo y hacia el prójimo. Paul Ballanfat (Estambul, Turquía) nos habló, asimismo, del peligro de extrapolar categorías políticas y culturales, y nos acercó a la realidad política de Turquía, que tiende a hacer desaparecer los elementos culturales y religiosos de las minorías y a homogeneizar una sociedad históricamente tan heterogénea como la turca. Celia López (Barcelona, España), retomó la figura de Llull para mostrar cómo el pensador, además de desarrollar un discurso cristiano filosófico, utiliza otros recursos provenientes de otras formas de religiosidad, ya sea la mística o la religión popular, que son comunes a las diferentes tradiciones. La mesa se cerró, nuevamente, con el debate de los ponentes que habían participado en dicha sesión.

Durante la tarde de ese mismo día tuvo lugar la última de las mesas temáticas, sobre «Cultura y Sociedades». Alexander Fidora (Barcelona, España) abrió este espacio haciendo hincapié en la importancia histórica de Llull como pensador político, al ser el primero en formular un plan para un Arbitraje Internacional y una Liga de Naciones en su Blaquerna, unos 25 años antes que Pierre Dubois. La primera réplica vino de la mano de Josep Maria Buades (São Paulo, Brasil), quien insistió en el universalismo de la religión cristiana y musulmana, abiertas a la conversión. También resaltó el espíritu pacifista de Llull, propiciado, no tanto por su conocimiento del Islam como por su conocimiento de los musulmanes, de las personas que profesaban esta doctrina. La siguiente réplica la llevó a cabo el rabino Alexandre Leone (São Paulo, Brasil) quien puso de relieve el contenido ético de la religión judía y la importancia de la Alianza de Noé, que concierne a las tres religiones monoteístas, y que sirvió a pensadores modernos como Emmanuel Lévinas o Theodor Herzl para defender el ideal de diálogo religioso. Por último, João Roberto da Costa e Silva (São Paulo, Brasil), haciendo referencia a autores como Habermas y Ratzinger, reivindicó la necesidad de una idea de tolerancia que comprenda aceptar y entender al otro, y defendió la necesidad de un estado que trabaje como legislador para corregir injusticias y a favor de la preservación de minorías. De nuevo la mesa se cerró con el debate, que insistió particularmente en la relación entre Llull y diversos autores modernos y contemporáneos.

Finalmente, la mañana del día siguiente sirvió para hacer balance y extraer algunas conclusiones que se habían alcanzado en el congreso, entre las cuales cabe destacar la vigencia de Llull como fuente de inspiración para cuestiones actuales y su importancia dentro de la historia del pensamiento: de la política, de la filosofía y de la religión. Además, el acercamiento a las distintas religiones nos mostró que ellas mismas definen su relación con la cultura de manera harto diversa. Sin embargo, sea cual sea la relación entre cultura y religión en las diferentes tradiciones, sí que comparten una misma tarea, a saber, la función correctiva (moral, social y política) que éstas, las religiones, tienen para con la sociedad.

Tras las conclusiones hubo unas palabras de João Sayad (São Paulo, Brasil), ex-ministro del gobierno de Brasil, quien recordó que el fin último de todas las religiones y, por lo tanto, su punto de convergencia es y debe ser la divinidad. Después de estas palabras, una muestra de música clásica otomana dio por finalizado el congreso.

Celia López Alcalde

ERC-Project «Latin into Hebrew» Universidad Autónoma de Barcelon 